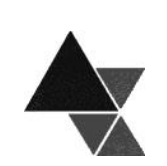

\title{
Tilosina: um importante antibiótico não monitorado em leite no Brasil
}

\author{
Rafaela Pinto da Costa ${ }^{1}$, Bernardete Ferraz Spisso ${ }^{2}$, Mararlene Ulberg Pereira ${ }^{3}$, Mychelle Alves \\ Monteiro ${ }^{4}$, Rosana Gomes Ferreira ${ }^{5}$, Betânia de Souza Carlos ${ }^{6}$, Angélica Castanheira de \\ Oliveira $^{7}$
}

A introdução de agentes antimicrobianos na alimentação animal revolucionou a produção de alimentos no mundo, porém o uso indiscriminado desses agentes podem provocar agravos à saúde da população. Os macrolídeos constituem a segunda classe de antimicrobianos mais usados nos animais em geral, sendo a tilosina presente em um maior número de formulações disponíveis para bovinos. A contaminação do leite por resíduos de tilosina acima dos valores considerados seguros pode constituir um risco potencial à saúde do consumidor. Com o objetivo de obter uma visão geral da atual situação da segurança de alimentos em relação a este problema, este estudo foi realizado mediante levantamento bibliográfico na base de dados SciFinder Scholar e periódicos CAPES. Foi constatado que no Brasil existem dois programas em andamento para avaliar a presença de resíduos de medicamentos veterinários em alimentos: PNCRC e PAMVet. Entretanto, a tilosina não consta no escopo analítico destes programas. Dos artigos que tratam da contaminação do leite por resíduos de tilosina publicados entre 2007 e 2013, oito abordam o monitoramento desta droga e vinte e dois o desenvolvimento/teste de performance de novas técnicas. Estes resultados alertam para que maior número de estudos de monitoramento da tilosina no leite seja realizado a fim de se estabelecer políticas de segurança alimentar e controle dessa substância, além de investigar se há uso indiscriminado desta droga.

Palavras-chave: leite, monitoramento, tilosina.

\section{Tylosin: an important antibiotic not monitored in milk in Brazil}

The use of antibiotics in animal feed has brought changes to food production worldwide, but the indiscriminate use of these drugs can be harmful to human beings. In general, macrolides are the second class of antibiotics most used in animals, in which tylosin is found in a large number of formulations available for livestock. Contaminated milk by residues of tylosin above safe values can become a potential risk to the health of consumers. Due to the purpose of having an overview of the current food safety situation regarding this problem, this study was done based on a bibliographical survey at database SciFinder Scholar and periodicals from CAPES. It was found that in Brazil, there are two current programs

\footnotetext{
${ }^{1}$ Mestre em Vigilância Sanitária, Laboratório de Resíduos de Medicamentos Veterinários, Departamento de Química, Instituto Nacional de Controle de Qualidade em Saúde (INCQS), Fundação Oswaldo Cruz, FIOCRUZ. Correspondência: Avenida Brasil no 4.365, Manguinhos, CEP: 21040-900, Rio de Janeiro, RJ.E-mail: rafaelapcosta@hotmail.com.

${ }^{2}$ Doutora em Vigilância Sanitária, Laboratório de Resíduos de Medicamentos Veterinários, Departamento de Química, INCQS, FIOCRUZ.

${ }^{3}$ Mestre em Vigilância Sanitária, Laboratório de Resíduos de Medicamentos Veterinários, Departamento de Química, INCQS, FIOCRUZ.

${ }^{4}$ Doutoranda em Ciências em Tecnologia de Processos Químicos e Bioquímicos, Laboratório de Resíduos de Medicamentos Veterinários, Departamento de Química, INCQS, FIOCRUZ.

${ }^{5}$ Mestre em Ciências em Tecnologia de Processos Químicos e Bioquímicos, Laboratório de Resíduos de Medicamentos Veterinários, Departamento de Química, INCQS, FIOCRUZ.

${ }^{6}$ Engenheira de Alimentos, Universidade Federal Rural do Rio de Janeiro (UFRRJ).

${ }^{7}$ Mestre em Química, Laboratório de Resíduos de Agrotóxicos em Alimentos, Departamento de Química, INCQS, FIOCRUZ.
} 
for evaluating the presence of residues of veterinary drugs in food: PNCRC and PAMVet. However, tylosin is not found in the analytical scope of these programs. Among the articles that evaluated milk contamination by tylosin residues published from 2007 to 2013, eight articles discuss the monitoring of this drug, and twenty two talk about new techniques of development / performance test. These results points to the need of having more monitoring studies of tylosin in milk in order to establish food security policies and control of this drug, so that indiscriminate use can be investigated.

Key-words: milk, monitoring, tylosin.

\section{INTRODUÇÃO}

Nos últimos anos, fatores econômicos e socioculturais determinaram alterações substanciais nos hábitos alimentares da população brasileira. Em meio à modernização dos padrões de vida, um número cada vez maior de consumidores está interessado em hábitos alimentares mais saudáveis e preocupado com a questão da segurança dos alimentos. Como consequência, os requisitos legais para a produção de alimentos de melhor qualidade e que não acarrete danos à saúde do consumidor tornaram-se cada vez mais rigorosos [1].

O Ministério da Saúde (MS), visando principalmente suprir o déficit nutricional da população brasileira, proporcionar benefícios à saúde e reduzir os gastos públicos, elaborou diretrizes para melhorar a qualidade da alimentação e, consequentemente, o estado nutricional da população. Por meio da Diretriz I, recomenda o consumo diário de leite e derivados para todas as faixas etárias por serem as principais fontes de cálcio na alimentação, contribuindo assim para um desenvolvimento saudável. Os diferentes tipos de leite, classificados como integral, semidesnatado e desnatado de acordo com o teor de gordura, e a quantidade desse alimento a ser ingerida devem ser adequados às diferentes fases do ciclo da vida. Três porções de leite e derivados devem ser consumidas diariamente e conter, preferencialmente, menores teores de gordura para os adultos e teor integral para crianças, adolescentes e gestantes [2].

Entende-se por leite, o produto oriundo da ordenha completa, ininterrupta sob condições satisfatórias de higiene, de vacas sadias, bem alimentadas e descansadas [3]. O leite, considerado um alimento funcional por Nikkhah, é rico em substâncias bioativas como aminoácidos essenciais, caseína, peptídeos, lactoalbuminas, imunoglobulinas, nucleosídeos, nucleotídeos, ácido linoleico conjugado, esfingomielina, vitaminas lipossolúveis e cálcio [4].

A indústria láctea é uma atividade de significativo impacto socioeconômico para o Brasil, pois o volume produzido e o consumo de leite e seus derivados têm crescido significativamente, sendo por isso alvo de vários programas de monitoramento [5]. De acordo com os dados da Projeção do Agronegócio Brasileiro 2012/2013 a 2022/2023 do Ministério da Agricultura, Pecuária e Abastecimento (MAPA) (Tabela 1), a produção de leite deve chegar a 41,304 milhões de litros em 2023, e o consumo projetado para este ano deve crescer 16,82\% em relação a 2013 chegando a 42,398 milhões de litros [6]. 
Tabela 1. Resultados da projeção da produção nacional de leite (2012/2013 a 2022/2023)

\begin{tabular}{lcccc}
\hline Produto & Ano & $\begin{array}{c}\text { Produção } \\
\text { (Milhões de Litros) }\end{array}$ & Ano & $\begin{array}{c}\text { Produção } \\
\text { (Milhões de litros) }\end{array}$ \\
\hline 2013 & 34,230 & 2019 & 38,538 \\
& 2014 & 35,017 & 2020 & 39,229 \\
& 2015 & 35,747 & 2021 & 39,921 \\
& 2016 & 36,464 & 2022 & 40,612 \\
& 2017 & 37,151 & 2023 & 41,304 \\
& 2018 & 37,845 & - & -
\end{tabular}

Fonte: Adaptado de Ministério da Agricultura, Pecuária e Abastecimento, 2014 [6].

Dentre as várias patologias que acometem a produção leiteira mundial, a mastite bovina pode ser considerada a mais comum e a mais onerosa para a exploração de animais de interesse zootécnico destinados à produção de leite, sendo, por isso, fundamental a prevenção, o controle e o tratamento dessa doença. Os prejuízos devem-se, principalmente, ao descarte do leite em consequência das alterações de sua composição e/ou pela presença de resíduos de antibióticos após o tratamento; à queda da produção total de leite; e aos gastos com antibióticos no tratamento dos animais acometidos. A doença causa ainda sofrimento ao animal além dos efeitos negativos sobre a qualidade do leite e derivados lácteos [7,8].

A mastite é uma inflamação da glândula mamária que se caracteriza por apresentar alterações patológicas no tecido glandular e uma série de modificações físico-químicas no leite, como a redução dos teores de cálcio, fósforo, proteína e gordura, e aumento de sódio e cloro [9,10]. Dentre os fatores que podem afetar a incidência e a etiologia da mastite estão o clima, a variação sazonal, a densidade populacional animal e o manejo ${ }^{[11]}$.

A etiologia da doença pode ser classificada como de origem tóxica, traumática, alérgica, metabólica ou infecciosa, sendo as causas infecciosas as de maior incidência, com destaque para as infecções bacterianas devido à maior frequência, embora fungos, algas e vírus possam também estar envolvidos no desenvolvimento da doença. Dentre os microorganismos bacterianos predominam o Staphylococcus sp. e o Streptococcus sp., responsáveis por cerca de 90 a $95 \%$ de todas as infecções dos rebanhos leiteiros. Para o controle da mastite, o uso de antimicrobianos por via intramamária ou sistêmica continua sendo a principal estratégia utilizada [9].

Os agentes antimicrobianos têm sido amplamente utilizados em animais produtores de alimentos para aumentar a taxa de ganho de peso, melhorar a eficiência alimentar e prevenir doenças [12]. A introdução desses agentes na dieta animal revolucionou a produção de alimentos no mundo, porém, devido ao seu uso indiscriminado em consequência da pressão pelo aumento da produção, seu emprego como promotor de crescimento está em discussão devido ao desenvolvimento de resistência a antimicrobianos e seu impacto na medicina humana. Em reunião conjunta entre as entidades internacionais, as Food and Agriculture Organization, World Health Organization e World Organization for Animal Health (FAO, WHO, OIE) reportaram que o uso dessas substâncias em subdoses pode criar condições favoráveis ao surgimento, persistência e difusão de micro-organismos antibiótico-resistentes [13].

A utilização dos agentes antimicrobianos na medicina humana e veterinária varia conforme a legislação adotada em cada país. Em 1998, a Comunidade Europeia proibiu o uso da tilosina como promotora de crescimento após reconhecer que o vasto uso dessa substância na alimentação animal contribui, a longo prazo, para a seleção de microorganismos resistentes e sua provável transferência para o homem ou dos seus genes de resistência para outros patógenos ${ }^{[14]}$. No Brasil, um grupo de trabalho 
reavaliou o uso de tilosina como aditivo e seu reflexo na Saúde Pública. Esse grupo concluiu que os dados relativos à toxicidade da tilosina não são relevantes do ponto de vista da decisão da proibição do seu uso como promotor de crescimento, portanto, a tilosina continua autorizada para uso no Brasil com esta finalidade [15]. Nos Estados Unidos, o uso da tilosina é aprovado tanto para fins terapêuticos como promotor de crescimento em animais. Em geral, no mundo inteiro as drogas mais utilizadas como promotores de crescimento incluem os macrolídeos (tilosina e espiramicina) dentre outras classes de antimicrobianos [16,17]. A Organização Mundial da Saúde (OMS) classificou os antibióticos macrolídeos como uma das três principais classes para o desenvolvimento de estratégias de gestão de risco a fim de preservar sua eficácia na medicina humana, já que a resistência pode emergir em patógenos zoonóticos como Campylobacter spp. e Staphylococcus aureus resistentes à Meticilina (MRSA, sigla em inglês) [18].

$\mathrm{O}$ uso indiscriminado de agentes antimicrobianos em animais podem provocar agravos à saúde humana devido à presença de seus resíduos em alimentos. A exposição prolongada a estes resíduos pela ingestão em pequenas quantidades por meio dos alimentos pode levar a efeitos indesejáveis diretos ou indiretos a humanos. Os efeitos diretos podem manifestar-se como:

- Alérgicos: sintomas alérgicos em indivíduos hipersensíveis;

- Citotóxicos: imunopatológicos, hepatotóxicos, nefrotóxicos e apresentar toxicidade para a medula óssea;

- Genotóxicos: carcinogenicidade e mutagenicidade;

- Desordens reprodutivas.

Os efeitos indiretos são igualmente
importantes e manifestam-se como:

- Desenvolvimento de micro-organismos resitentes a antimicrobianos usados na terapia humana ${ }^{[1,16]}$.

Além dos fatores indesejáveis à saúde, os resíduos em alimentos comprometem relações comerciais internacionais de produtos in natura $\mathrm{e}$ processados de origem animal demonstrando a importância do monitoramento e controle de resíduos de antibióticos no leite. Para proteger a saúde do consumidor, prevenir a emergência de microorganismos resistentes a antimicrobianos e, até mesmo, embargos comerciais, Limites Máximos de Resíduos (LMR) foram estabelecidos por agências regulatórias [20,21]. Entende-se como LMR a concentração máxima (expressa em $\mathrm{mg} / \mathrm{kg}, \mu \mathrm{g} / \mathrm{kg}$, $\mathrm{mg} / \mathrm{l}$ ou $\mu \mathrm{g} / \mathrm{l})$ permitida legalmente ou reconhecidamente admissível de resíduos em um alimento [22].

Para evitar a presença de resíduos no leite em concentrações nocivas à saúde humana, é necessário determinar o período em que o medicamento estará sendo eliminado nesse fluido (período de carência), que deve ser indicado na bula, e que varia de acordo com o produto utilizado, em conformidade com as Boas Práticas Agropecuárias (BPA). Geralmente produtos para vacas em fase seca são desenvolvidos para permanecerem por algumas semanas no úbere, por isso apresentam maior período de carência que os produtos para vacas em lactação ${ }^{[23]}$.

Os antibióticos macrolídeos são compostos bacteriostáticos caracterizados por um anel lactona macrocíclico contendo 14, 15 ou 16 átomos com açúcares ligados por ligações glicosídicas. Atuam ligando-se reversivelmente à subunidade ribossômica $50 \mathrm{~S}$, particularmente na molécula $23 \mathrm{~S}$ do RNA, inibindo a síntese proteica direcionada pelo $\mathrm{RNA}_{\mathrm{m}}$, estimulando assim, a dissociação do peptidil-RNA $A_{t}$ dos ribossomos durante a translocação. Os macrolídeos mais comumente usados são: eritromicina, oleandomicina, roxitromicina, diritromicina, claritromicina, fluritromicina, azitromicina, josamicina, rosaramicina, roquitamicina, quitasamicina, miromicina, espiramicina e tilosina ${ }^{[24,25]}$.

Os macrolídeos constituem a segunda classe de antimicrobianos quantitativamente mais usados nos animais em geral, perdendo somente para as tetraciclinas [17]. No Brasil, os antibióticos macrolídeos estão disponíveis para o tratamento de diversas infecções bacterianas agudas e crônicas em animais. Existem relatos da ocorrência de distúrbios gastrointestinais, reações de hipersensibilidade e inibição do metabolismo hepático, porém, não há ainda evidências de efeitos tóxicos mais graves devido ao uso de antibióticos macrolídeos [26]. A tilosina, tilmicosina e espiramicina são antimicrobianos macrolídeos que possuem aplicações para animais da espécie bovina, a josamicina somente para aves e a azitromicina para animais de companhia (caninos e felinos). Nesta classe 
de antibióticos, tem sido observado um predomínio no mercado brasileiro, de tilosina nas formulações dos medicamentos indicados para o tratamento da mastite [27].

A tilosina $\left(\mathrm{C}_{46} \mathrm{H}_{77} \mathrm{NO}_{17}\right)$ é um antibiótico macrolídeo de amplo espectro, de massa molecular $916,1 \mathrm{~g} / \mathrm{mol}$ que apresenta atividade contra a maioria das bactérias gram-positivas e diferentes membros de Mycoplasma spp. Mostra-se ativo também contra alguns micro-organismos gram-negativos e membros do grupo Chlamydia spp., sem, entretanto, apresentar atividade contra bactérias do gênero Enterobacteriaceae. Do ponto de vista farmacocinético é classificada como uma base orgânica fraca $(\mathrm{pKa}=7,73)$ que rapidamente forma sais $\mathrm{e}$ ésteres. Constitui-se de uma mistura de quatro antibióticos macrolídeos produzidos por cepas de Streptomyces fradiae. O principal componente da mistura é a tilosina A (mais de 80\%), embora as tilosinas B, C e D possam também estar presentes. A tilosina A (Figura 1) contém uma lactona policética (tilactona) substituída com três açúcares 3-deoxiexose [25].

Figura 1: Estrutura química da tilosina A.

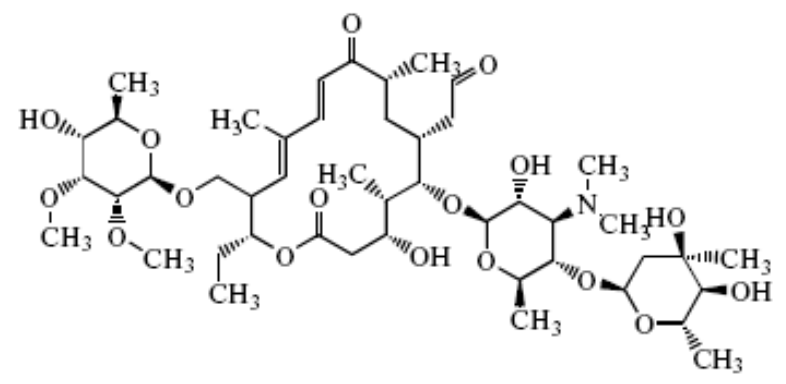

Fonte: Sanli S et al, 2011 [47].

As formas da tilosina disponíveis são: tilosina base, tartarato de tilosina e fosfato de tilosina. No Brasil, assim como em vários países, a tilosina está registrada para uso exclusivo na medicina veterinária. $\mathrm{Na}$ pecuária, permite-se sua administração através do alimento, da água ou por via intramuscular com a finalidade de aumentar o ganho de peso; melhorar a eficiência alimentar e reduzir a incidência de abscessos no figado (doses de 50-100mg/animal/dia); prevenir a pneumonia associada ao micoplasma e à Pasteurella multocida em bezerros (doses de $1 \mathrm{~g} /$ animal duas vezes ao dia); e no tratamento da pneumonia, podridão dos cascos, difteria, metrite e mastite aguda em animais adultos (doses de $5-10 \mathrm{mg} / \mathrm{kg} / \mathrm{dia}$ por via intramuscular) [25].

O não cumprimento das orientações de administração da tilosina pode resultar na presença de níveis elevados de resíduos desta droga em tecidos animais comestíveis e no leite. Estes resíduos podem causar efeitos tóxicos aos consumidores, como reações alérgicas em indivíduos sensíveis, provocar o desenvolvimento de bactérias antibiótico-resistentes e induzir a resistência cruzada entre outros antibióticos de estrutura ou mecanismo de ação similar, tornando mais difícil o tratamento de determinadas infecções. Contudo, a resistência bacteriana é a principal preocupação em relação ao uso da tilosina e demais macrolídeos [28,29].

A contaminação do leite por agentes químicos em índices acima dos considerados seguros, incluindo os resíduos de medicamentos veterinários frequentemente usados no tratamento da mastite ou como promotores de crescimento, pode se constituir em um risco potencial à saúde do consumidor. $\mathrm{O}$ MAPA, por meio da Instrução Normativa no 62/2011, proíbe o envio de leite de animais a estabelecimentos industriais para beneficiamento que estejam sendo submetidos ao tratamento com medicamentos de uso veterinário passíveis de eliminação pelo leite, motivo pelo qual devem ser afastados da produção pelo período recomendado pelo fabricante. Dessa forma visa-se assegurar que os resíduos da droga não sejam superiores aos níveis definidos por meio de normas específicas ${ }^{[3]}$.

O Brasil, membro efetivo da Food and Agriculture Organization (FAO), do Codex Alimentarius e signatário da World Organization for Animal Health (OIE), tem participado ativamente das discussões ligadas ao uso de antimicrobianos, incorporando, em suas ações regulatórias, as recomendações consideradas pertinentes. Diversas autoridades regulatórias, tais como a European Medicines Agency (EMA), a United States Departament of Agriculture (USDA) e, no Brasil, a Agência Nacional de Vigilância Sanitária (ANVISA) e o Ministério da Agricultura, Pecuária e Abastecimento (MAPA) têm estabelecido regulamentos para determinar os Limites Máximos de Resíduos (LMR) (Tabela 2) [30].

Somente em outubro de 2012, com base no padrão limite acordado pelos países que compõem o Mercado Comum do Sul (Mercosul), a ANVISA, por meio da RDC no 53/2012 incorpora ao ordenamento 
jurídico nacional a Resolução GMC MERCOSUL no $54 / 2000$ que regulamenta o limite de resíduos de medicamentos veterinários que poderão ser encontrados em alimentos de origem animal [31,32].
Além de definir limites máximos de resíduos, a RDC no 53/2012 estabelece valores de ingestão diária admissível e metodologias de análise para avaliar a presença destes resíduos ${ }^{[32] .}$

Tabela 2. Limites Máximos de Resíduos (LMR) de antimicrobianos macrolídeos para o leite

\begin{tabular}{cccccc}
\hline Família & Molécula & \multicolumn{4}{c}{ LMR } \\
\cline { 3 - 6 } & & ANVISA & EMA & CODEX & USDA \\
\hline \multirow{2}{*}{ Macrolídeos } & Tilosina & - & $50 \mu \mathrm{g} / \mathrm{kg}$ & $100 \mu \mathrm{g} / \mathrm{kg}$ & $50 \mu \mathrm{g} / \mathrm{kg}$ \\
& Espiramicina & - & $200 \mu \mathrm{g} / \mathrm{kg}$ & $200 \mu \mathrm{g} / \mathrm{l}$ & - \\
& Eritromicina & $40 \mu \mathrm{g} / \mathrm{kg}^{*}$ & $40 \mu \mathrm{g} / \mathrm{kg}$ & - & $50 \mu \mathrm{g} / \mathrm{kg}$ \\
& Novobiocina & - & $50 \mu \mathrm{g} / \mathrm{kg}$ & - & $100 \mu \mathrm{g} / \mathrm{kg}$ \\
& Pirlimicina & - & $100 \mu \mathrm{g} / \mathrm{kg}$ & $100 \mu \mathrm{g} / \mathrm{kg}$ & $400 \mu \mathrm{g} / \mathrm{kg}$ \\
& Tilmicosina & - & $50 \mu \mathrm{g} / \mathrm{kg}$ & - & -
\end{tabular}

*Referência do Mercosul [31]

Fonte: USDA, 2012 [30].

É importante realçar os diferentes valores de LMR estabelecidos para a tilosina pela EMA, CODEX e USDA, que variam de 50 a $100 \mu \mathrm{g} / \mathrm{kg}$ devido às diferentes avaliações de risco empregadas pelas agências e blocos econômicos.

Uma revisão realizada por Ferreira em 2012 revelou que de trinta e três publicações sobre o monitoramento de resíduos de antimicrobianos em leite, somente três $(9,1 \%)$ citavam os antimicrobianos macrolídeos, reforçando a necessidade de um estudo mais detalhado sobre essa classe [33].

Considerando o amplo emprego da tilosina na medicina veterinária no tratamento de diversas doenças e como promotor de crescimento, seu impacto sobre a cadeia produtiva de leite, as implicações na Saúde Pública e a escassez de trabalhos disponíveis na literatura sobre a qualidade do leite em relação a este antimicrobiano no Brasil, espera-se com este trabalho contribuir para a importância do monitoramento de resíduos de tilosina no leite, uma vez que estas ações são indispensáveis para direcionar políticas públicas e ações corretivas visando à saúde do consumidor e a qualidade do leite, cooperando para a segurança alimentar e qualidade nutricional [34].

\section{METODOLOGIA}

Em busca da identificação quantitativa de pesquisas realizadas até o momento sobre resíduos do antibiótico macrolídeo tilosina em leite no Brasil, trabalhos já desenvolvidos foram consultados.

Um extenso levantamento de trabalhos que tratam de resíduos de antimicrobianos em leite, especificamente a tilosina, foi elaborado considerando as bases de dados textuais e referenciais disponíveis na internet. A estratégia de busca contou com artigos indexados na base de dados SciFinder Scholar e periódicos CAPES, além de consultas aos sítios eletrônicos da ANVISA e do MAPA, que serviram de base para o desenvolvimento deste trabalho.

O descritor utilizado na busca foi: "tylosin residue". Realizado o levantamento bibliográfico, os trabalhos durante o período de 2007 a 2013 foram separados e os dados organizados em tabelas de acordo com a técnica utilizada e a abordagem do trabalho (monitoramento, desenvolvimento e/ou teste de performance). 


\section{RESULTADOS E DISCUSSÃO}

No Brasil ainda são escassos os trabalhos disponíveis na literatura sobre a qualidade do leite em relação à tilosina. Ainda assim, foi possível realizar um levantamento considerável de publicações, contribuindo para o fornecimento de uma visão geral da atual situação da segurança alimentar em relação a este problema.

Existem dois programas nacionais em andamento com o propósito de avaliar a presença de resíduos de medicamentos veterinários em alimentos: no âmbito do MAPA, o Plano Nacional de Controle de Resíduos e Contaminantes em Produtos de Origem Animal (PNCRC), onde está inserido o Programa de Controle de Resíduos em Leite (PCRL); e no âmbito da ANVISA, o Programa de Análise de Resíduos de Medicamentos Veterinários em Alimentos de Origem Animal (PAMVet). O PNCRC tem como objetivo garantir a produção e a produtividade do leite no território nacional, bem como o aporte de produtos similares importados e o PAMVet visa operacionalizar sua competência legal de controlar e fiscalizar resíduos de medicamentos veterinários em alimentos, tendo o leite como primeira matriz de análise. Esse programa complementa as ações já desenvolvidas pelo MAPA, no setor primário, pois avalia o produto no momento do consumo, tal como este é apresentado para o consumidor ${ }^{[35,36] \text {. }}$

Os critérios de seleção de medicamentos veterinários a serem investigados pelo PAMVet incluem, no geral, os passíveis de eliminação na forma de resíduos nos alimentos; aqueles cuja presença no alimento ofereça um risco potencial à saúde humana e os utilizados para fins veterinários que impliquem em elevado potencial de exposição do consumidor, além de disponibilidade de metodologia analítica confiável, sensível, prática e de custo acessível para o desenvolvimento do programa de controle. O PNCRC preocupa-se, ainda, com as implicações com o comércio internacional, adotando na sua seleção os resíduos que possam constituir barreiras às exportações de produtos de origem animal.

Em 2014, foi publicada a Instrução Normativa no 11 do MAPA que aprovou o escopo analítico para o monitoramento dos produtos de origem animal (leite, carnes, pescado, ovos, mel e avestruzes) neste ano. A tilosina não constou no escopo analítico do PNCRC/Leite desde o primeiro exercício em 2006 até o último publicado em 2014, e somente o macrolídeo eritromicina foi incluído no PAMVet até o momento, sendo estes os dois únicos programas de monitoramento no Brasil para controle dessas substâncias nos alimentos [36,37].

Embora a disponibilidade da tilosina para uso tanto como agente promotor de crescimento (quando administrado em doses subterapêuticas), como no tratamento de infecções em bovinos seja uma realidade, ainda permanece sem monitoramento pelos atuais programas nacionais.

Um requisito essencial para programas de avaliação de resíduos de antimicrobianos no leite é a disponibilidade de testes analíticos precisos e efetivos. Foram encontrados nesse estudo 30 artigos que tratam da contaminação do leite de várias espécies animais por resíduos de tilosina publicados entre 2007 e 2013. A Tabela 3 apresenta os resultados da pesquisa bibliográfica relacionando os autores dos trabalhos encontrados, ao ano de publicação, abordagem do trabalho e técnica utilizada. Nota-se que diferentes métodos baseados em técnicas variadas têm sido descritos para determinação do antibiótico macrolídeo tilosina no leite e poucos trabalhos sobre o monitoramento dos resíduos deste antimicrobiano estão disponíveis. Os trabalhos encontrados contemplam técnicas cromatográficas, imunoquímicas e microbiológicas (ensaios de inibição do crescimento microbiano). 
Tabela 3. Resultados da pesquisa bibliográfica sobre artigos que tratam da contaminação do leite por resíduos de tilosina no período entre 2007 e 2013

\begin{tabular}{|c|c|c|c|c|}
\hline \multirow{2}{*}{ Ano } & \multirow{2}{*}{ Abordagem do trabalho } & \multicolumn{3}{|c|}{ Técnica adotada } \\
\hline & & Cromatográfica & Microbiológica & Imunoquímica \\
\hline 2013 & $\begin{array}{c}\text { Monitoramento } \\
\text { Desenvolvimento/Teste de Performance }\end{array}$ & $\begin{array}{c}- \\
- \\
{[38]}\end{array}$ & $\begin{array}{c}- \\
{[39]}\end{array}$ & - \\
\hline 2012 & $\begin{array}{c}\text { Monitoramento } \\
\text { Desenvolvimento/Teste de Performance }\end{array}$ & - & - & - \\
\hline 2011 & $\begin{array}{c}\text { Monitoramento } \\
\text { Desenvolvimento/Teste de Performance }\end{array}$ & $\begin{array}{c}{[42]} \\
{[46] ;[47]}\end{array}$ & $\begin{array}{l}{[42]} \\
{[48]}\end{array}$ & $\begin{array}{c}{[43] ;[44] ;[45] ;[42]} \\
{[49]}\end{array}$ \\
\hline 2010 & $\begin{array}{c}\text { Monitoramento } \\
\text { Desenvolvimento/Teste de Performance }\end{array}$ & $\begin{array}{c}{[28]} \\
{[50] ;[51]}\end{array}$ & $\begin{array}{l}- \\
-\end{array}$ & $\begin{array}{l}- \\
-\end{array}$ \\
\hline 2009 & $\begin{array}{c}\text { Monitoramento } \\
\text { Desenvolvimento/Teste de Performance }\end{array}$ & $\begin{array}{c}- \\
{[52]}\end{array}$ & - & - \\
\hline 2008 & $\begin{array}{c}\text { Monitoramento } \\
\text { Desenvolvimento/Teste de Performance }\end{array}$ & $\begin{array}{c}{[55]} \\
{[56] ;[57]}\end{array}$ & - & 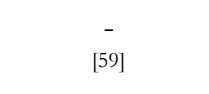 \\
\hline 2007 & $\begin{array}{c}\text { Monitoramento } \\
\text { Desenvolvimento/Teste de Performance }\end{array}$ & $\begin{array}{c}- \\
{[60]}\end{array}$ & - & - \\
\hline & Total de Publicações & 13 & 9 & 8 \\
\hline
\end{tabular}

Fonte: Elaboração dos autores.

As técnicas analíticas usadas pelas indústrias de laticínios estão em constante mudança devido a potencial presença de resíduos de antimicrobianos no leite, sendo esta evolução iniciada pelo aumento da capacidade de detecção dos métodos de análises [63].
Ye Bang-Ce e col. (2008) e mais recentemente Peng e col. (2012) realizaram em seus trabalhos um estudo comparativo entre técnicas microbiológicas, cromatográficas e imunoensaios (Quadro 1) disponíveis para determinação de tilosina em nível residual em produtos de origem animal [59,41].

Quadro 1. Comparação de técnicas para a determinação de tilosina em leite

\begin{tabular}{|c|c|c|c|}
\hline Técnicas & Microbiológicas & Cromatográficas & Imunoensaios \\
\hline Características & $\begin{array}{c}\text { São demoradas; pouco } \\
\text { sensíveis aos diversos } \\
\text { grupos de antibióticos; e } \\
\text { não permitem a } \\
\text { identificação de substâncias. }\end{array}$ & $\begin{array}{c}\text { São caras, demoradas e, } \\
\text { portanto, limitadas a fins de } \\
\text { confirmação. }\end{array}$ & $\begin{array}{c}\text { determinações de rotina; e } \\
\text { apresentam alta } \\
\text { sensibilidade; baixo custo e } \\
\text { capacidade de triagem de } \\
\text { um grande número de } \\
\text { amostras. }\end{array}$ \\
\hline
\end{tabular}

Fonte: Ye Bang-Ce e col.[59]; Peng e col. [41]. 
Sanli e col. (2011) e García-Mayor e col. (2012) concluíram que a determinação dos macrolídeos tem sido tradicionalmente realizada por ensaios microbiológicos e imunoensaios. Estes métodos são excelentes como meios semiquantitativos de triagem de quantidades residuais de macrolídeos em amostras de leite, porém não são suficientemente específicos para assegurar a identificação precisa das drogas residuais nos tecidos animais. Para superar estes problemas, as análises cromatográficas, tais como a Cromatografia Líquida de Alta Eficiência com detector de Ultravioleta (CLAE-UV), com detecção electroquímica, e mais recentemente a Espectrometria de Massas (EM), considerada o meio de detecção mais universal, além da eletroforese capilar têm sido relatadas para a determinação de macrolídeos [47,29].

Com o crescente desenvolvimento tecnológico para a determinação de resíduos em alimentos, os cientistas Wang e Leung (2007) demonstraram grande interesse pelas aplicações da LC (Liquid Chromatography) e da UPLC (Ultra Performance Liquid Chromatography) acopladas ao espectrômetro de massas TOF-MS (Time of Flight-Mass Espectrometry), ou Q-TOF (Quadrupolo-TOF), na análise de constituintes traço em misturas complexas como os alimentos, devido à possibilidade de confirmação da presença destes contaminantes e sua identificação. Neste mesmo ano, os pesquisadores relataram a escassez de trabalhos publicados na análise de resíduos de antibióticos em alimentos usando as técnicas LCTOF/MS ou Q-TOF [60].

Em 2008, Aguilera-Luiz e col. também observaram que as técnicas de detecção convencionais, como a CLAE-UV, estavam sendo substituídas pela detecção por EM pois as agências de saúde pública dependiam da confirmação inequívoca dos antibióticos no gênero alimentício. Conclui-se assim, que a CLAE acoplada ao simples ou triplo quadrupolo é a técnica mais promissora para a análise dos antibióticos nos alimentos, uma vez que permite a sua quantificação e confirmação em quantidades vestigiais, conforme previu Wang e Leung (2007), embora outros analisadores como TOF também possam ser usados $[57,60]$.

Atentos à emergente tendência na análise de resíduos, Clark e Storey (2011) desenvolveram métodos capazes de monitorar uma grande variedade de compostos, independente da classe do analito, em uma única amostra. Cada vez mais, pesquisadores desenvolvem em seus laboratórios métodos que envolvem etapas de extração e clean up combinados à sensibilidade e seletividade de um Cromatógrafo a Líquido de Alta Eficiência acoplado à Espectrometria de Massas Sequencial (CLAE-EM/EM). A vantagem de um método de triagem multiclasse e multirresíduo é a sua fácil adaptação para a detecção de diferentes compostos conforme a necessidade. Um exemplo é o método proposto por Clark e Storey que permitia o monitoramento de 25 analitos alvo e foi expandido aumentando sua capacidade de monitorar novos compostos [46].

Contudo, a escolha da técnica mais adequada em conformidade com a finalidade do estudo verificando-se o custo-benefício dos procedimentos analíticos disponíveis são os principais pontos comuns a todos os laboratórios envolvidos na análise de resíduos em alimentos. No geral, técnicas cromatográficas são preferidas para fins de monitoramento e confirmação de drogas veterinárias em alimentos, enquanto imunoensaios são mais usados aos procedimentos de triagem de rotina, como no caso das indústrias de laticínios, embora uma forma de melhorar a eficácia seja a maximização do número de analitos que possam ser determinados em um único processo (técnica multi-resíduo) como no caso da CLAE-EM/EM.

Durante o desenvolvimento desta revisão bibliográfica, foram identificados apenas oito trabalhos relacionados ao monitoramento de resíduos de tilosina no leite, enquanto a maioria aborda o desenvolvimento, teste de performance e validação de novas metodologias para a avaliação da qualidade do leite quanto à concentração deste antimicrobiano. A fim de verificar o atendimento aos níveis estabelecidos de resíduos de drogas veterinárias no leite, Gradinaru e col. (2011) realizaram um estudo de monitoramento durante o período de 2006 a 2009 na cidade de Moldavia (Romênia). Neste estudo, foram efetuados testes de triagem por ensaios microbiológicos em 2785 amostras de leite coletadas junto aos estabelecimentos industriais. Os resultados positivos e os inconclusivos foram confirmados por imunoensaios $(n=172)$, revelando a contaminação por tilosina no leite em 13 amostras (7,56\%) durante os quatro anos de pesquisa (Tabela 4). A concentração média encontrada variou entre 89,80 a 105,75 $\mu \mathrm{g} / \mathrm{kg}$ de tilosina. Alguns destes resultados superam o LMR $(100 \mu \mathrm{g} / \mathrm{kg})$ estabelecido pelo Codex Alimentarius, indicando o mau uso dessa substância pelos produtores locais [43]. 
Tabela 4. Família de antibióticos identificados em amostras confirmadas por Gradinaru e col. (2011)/Romênia ${ }^{[43]}$.

\begin{tabular}{ccccccccccccc}
\hline \multirow{2}{*}{ Ano } & \multicolumn{2}{c}{$\beta$ - lactâmicos } & \multicolumn{2}{c}{$\begin{array}{c}\text { Gentamicina / } \\
\text { Neomicina }\end{array}$} & \multicolumn{2}{c}{$\begin{array}{c}\text { Gentamicina / } \\
\text { Estreptomicina }\end{array}$} & Macrolídeos & Tetraciclinas & \multicolumn{2}{c}{ Total } \\
\cline { 2 - 12 } & № & \% & № & $\%$ & № & $\%$ & № & $\%$ & № & $\%$ & № & $\%$ \\
\hline 2006 & 17 & 29,31 & 12 & 20,69 & 10 & 17,24 & 5 & 8,62 & 14 & 24,14 & 58 & 100 \\
2007 & 13 & 29,54 & 12 & 27,27 & 5 & 11,36 & 3 & 6,82 & 11 & 25,00 & 44 & 100 \\
2008 & 9 & 20,93 & 11 & 25,58 & 8 & 18,60 & 3 & 6,97 & 12 & 27,91 & 43 & 100 \\
2009 & 9 & 33,33 & 8 & 29,63 & 3 & 11,11 & 2 & 7,41 & 5 & 18,52 & 27 & 100 \\
\hline
\end{tabular}

No monitoramento realizado por Karamibonari e Movassagh (2011), foram realizadas 68 análises de leite pasteurizado coletado de estabelecimentos comerciais da cidade de Tabriz (Irã), por imunoensaio. Os resultados (Tabela 5) revelam que em 12 amostras a concentração de tilosina variou entre 3 e $10 \mathrm{ng} / \mathrm{mL}$ e 35 amostras apresentaram resultados entre 10 e $30 \mathrm{ng} / \mathrm{mL}$, todos abaixo do LMR permitido pela União Europeia (UE) (50 $\mu \mathrm{g} / \mathrm{kg}$ ), enquanto em 21 amostras a tilosina não foi detectada, indicando que essa substância tem sido utilizada, ainda que, neste estudo, as concentrações encontradas sejam aceitáveis ${ }^{[44]}$.

Tabela 5. Resultados do monitoramento de tilosina em leite pasteurizado realizado por Karamibonari e Movassagh (2011) [44]

\begin{tabular}{cc}
\hline Faixa de concentração de tilosina $(\mathbf{n g} / \mathbf{m L})$ & No de amostras \\
\hline Não detectado & 21 \\
$0,5-3$ & 0 \\
$3-10$ & 12 \\
$10-30$ & 35 \\
$>30$ & 0 \\
Acima do LMR estabelecido pela UE \\
Faixa (0-23)
\end{tabular}

Movassagh, em um estudo anterior, realizou testes em 50 amostras de leite coletadas aleatoriamente de centros de coleta do subúrbio da cidade de Parsabad (Irã) no período de março a maio de 2009. Neste monitoramento foi utilizado o Copantest, cujo limite de detecção para o macrolídeo tilosina é de 50$100 \mathrm{ng} / \mathrm{kg}$. Este kit consiste em um método microbiológico baseado na inibição do crescimento do B. stearothermophilus na presença de resíduos de antimicrobianos no leite. Esses métodos, geralmente, não fazem distinção entre os membros de uma classe de antibióticos, mas fornecem uma estimativa semiquantitativa do total de resíduos detectados. As vantagens deste método é sua alta sensibilidade, baixo 
custo e simplicidade de uso, por isso continuam a ser utilizados principalmente nos testes de triagem. Do total de amostras, 14\% apresentaram resultados positivos para a presença de resíduos de antibióticos no leite da região em estudo [45].

Figura 2. Porcentagem de amostras positivas para resíduos de antibióticos em leite de vaca da região de Parsabad/Irã

\section{Amostras Positivas}

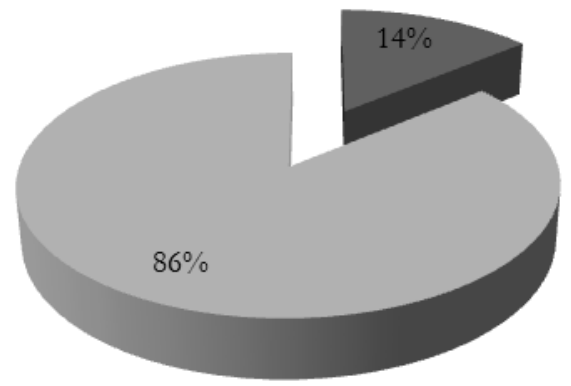

Amostras com resíduos de antibióticos

- Amostras livres de resíduos de antibióticos

Fonte: Adaptado de Movassagh, 2011 [45]

Conforme os resultados obtidos nesse trabalho, informações publicadas sobre a situação da tilosina no leite no Brasil ainda não estão disponíveis. Uma vez relatada a presença de tilosina em leite em outros países, esta pesquisa deveria ser aplicada no Brasil. Para isto, mais estudos de monitoramento de tilosina no leite deveriam ser realizados, já que esta substância não foi contemplada pelos atuais programas de monitoramento governamentais. A implementação de pesquisas revelariam a real situação brasileira frente ao uso desse antimicrobiano e com isso atenderia aos critérios de seleção de drogas a serem monitoradas pelos programas nacionais em andamento.

Do ponto de vista da produção animal, as principais consequências do mau uso dessas substâncias são a provável falha dos programas de controle de doenças e da recuperação clínica dos animais, o aumento da gravidade das doenças, morbidade prolongada, aumento da mortalidade e redução da produtividade. Todos estes aspectos geram custos para a sociedade, como a redução da oferta e da qualidade dos alimentos, do número de empregos, da geração de renda e do crescimento econômico do país, além das repercussões indesejáveis à saúde do consumidor como o prolongamento de doenças, falhas no tratamento, aumento da gravidade da doença e até mesmo a morte causada por patógenos de origem alimentar (principalmente Campylobacter spp. e Salmonella spp.) resistentes aos antimicrobianos disponíveis para o tratamento de enfermidades [13]. Pelos motivos apresentados, o controle de resíduos de antibióticos em alimentos, a fim de se constituir um programa de vigilância e o conhecimento da dimensão da exposição da população a estes compostos, é de fundamental importância para direcionar as ações de controle visando à proteção do consumidor.

Além de programas de vigilância para a supervisão do uso de antimicrobianos na produção de alimentos e do controle da venda dessas substâncias, métodos internacionais normalizados devem ser empregados, como o estabelecimento de limites máximos de resíduos (LMR). O Brasil ainda não possui um LMR estabelecido para a tilosina em leite, embora esses valores já tenham sido estabelecidos pelo Codex Alimentarius, pela União Europeia e pelos Estados Unidos. 
Contudo, para impedir restrições ao comércio internacional de alimentos decorrentes da presença de resíduos de tilosina acima dos limites estabelecidos por autoridades regulatórias e garantir ao consumidor a aquisição de alimentos com atributos nutricionais e sanitários adequados às suas necessidades, ou seja, de boa qualidade nutricional e livres de contaminação química, biológica ou física, ações conjuntas entre o setor público, organismos não governamentais e consumidores são fundamentais. Para harmonizar a questão da segurança alimentar e nutricional entre países, o Codex Alimentarius desenvolve normas internacionais para alimentos baseado em princípios científicos-tecnológicos onde diversos medicamentos veterinários têm sido avaliados e limites máximos de resíduos estabelecidos.

Frente a essa discussão, o presente estudo visa contribuir com dados no campo científico para o aperfeiçoamento dos sistemas de controle, prevenção e inspeção já estabelecidos no Brasil.

\section{CONSIDERAÇÕES FINAIS}

Sabendo-se que o uso de macrolídeos, em especial a tilosina, é mundialmente difundido, mais estudos de monitoramento de resíduos de tilosina no leite devem ser realizados para verificar o uso desse antimicrobiano na pecuária leiteira e, a partir desses dados direcionar ações públicas e corretivas para que esse macrolídeo não represente risco à saúde do consumidor através do consumo de leite. Portanto, os resultados deste trabalho evidenciam a importância da inclusão da tilosina nos atuais programas de monitoramento de leite do Brasil a fim de verificar o uso abusivo desta substância, já que metodologias analíticas diversificadas encontram-se disponíveis na literatura.

\section{REFERÊNCIAS}

[1] Baptista P, Antunes C. Higiene e Segurança Alimentar na Restauração: ficha Técnica. Volume II - Avançado [internet]. Lisboa: ESAC; 2005 [acesso em 02 mar 2012]. Disponível em: http://www.esac.pt/noronha/manuais/restaura $\% \mathrm{C} 3 \% \mathrm{~A} 7$ $\%$ C3\%A3o_VOL_2.pdf

[2] Brasil. Ministério da Saúde. Secretaria de Atenção à Saúde. Guia Alimentar para População Brasileira: promovendo a alimentação saudável [internet]. Brasília: Ministério da Saúde; 2012 [acesso em 21 abril 2012]. Disponível http://dtr2001.saude.gov.br/editora/produtos/livros/pdf/ 05_1109_M.pdf

[3] Brasil. Ministério da Agricultura, Pecuária e Abastecimento. Instrução Normativa no 62 , de 29 de dezembro de 2011. Aprova os Regulamentos Técnicos de Produção, Identidade e Qualidade do Leite tipo A, do Leite tipo B, do Leite tipo C, do Leite Pasteurizado e do Leite Cru Refrigerado e o Regulamento Técnico da Coleta de Leite Cru Refrigerado e seu Transporte a Granel. Diário Oficial da União. 30 dez 2011. Seção 1, p. 6 -11.

[4] Nikkhah A. Milk products and postmodern humans: public education fundamentals. Food and Nutrition Sciences. 2011;2(3):222-4.

[5] Beltrane MA, Machinski Junior M. Principais Riscos Químicos no Leite: um problema de Saúde Pública. Arq. Ciênc. Saúde Unipar. 2005;9(2):141-5.

[6] Brasil. Ministério da Agricultura, Pecuária e Abastecimento. Brasil Projeções do Agronegócio 2012/2013 a 2022/2023. Projeções de longo prazo. Brasilia: Assessoria de Gestão Estratégica; 2014 [acesso em 09 maio 2014]. Disponível em: http://www.agricultura.gov.br/arq_editor/projecoes\%20at ualizada.pdf.

[7] Pilon L, Duarte KMR. Técnicas para detectar resíduos de antibiótico em leite bovino. Pubvet. 2010;4(42).

[8] Chagunda MGG, Friggens NC, Rasmussen MD, Larsen T. A model for detection of individual cow mastitis based on an indicator measured in milk. J. Dairy Sci. 2006;89(8):2980-98.

[9] Peres NF, Zappa V. Mastite em vacas leiteiras: revisão de literatura. Revista Científica Eletrônica de Medicina Veterinária [periódico na internet]. 2011 [acesso em 20 abr 2013];9(16). Disponível em: http://www.revista.inf.br/veterinaria16/revisao/RV17.pdf.

[10] Tozzetti DS, Bataier MBN, Almeida LR, Piccinin A. Prevenção, controle e tratamento das mastites bovinas: revisão de literatura. Revista Científica Eletrônica de Medicina Veterinária [periódico na internet]. 2008 [acesso em 15 abr 2013];4(10). Disponível em: http://www.revista.inf.br/veterinaria10/revisao/edic-vin10-RL74.pdf.

[11] The Merck Veterinary Manual. Mastitis in cattle: an overview [acesso em 20 jan 2012]. Disponível em: http://www.merckvetmanual.com/mvm/index.jsp?cfile $=$ ht $\mathrm{m} / \mathrm{bc} / 110902 . \mathrm{htm}$ 
[12] Tong J, Rao Q, Zhu K, Jiang Z, Ding S. Simultaneous determination of five tetracycline and macrolide antibiotics in feeds using HPCE. J. Sep. Sci. 2009;32(23-24):4254-60.

[13] FAO. Animal Production and Health. FAO supports measures to minimize and contain antimicrobial resistance [internet]. 2012 [acesso em 07 jul 2012]. Disponível em: http://www.fao.org/ag/againfo/home/en/news_archive/2 011_04_AMR.html

[14] União Europeia. Regulamento (CE) no $2821 / 98$ do conselho de 17 de dezembro de 1998. Altera, no que diz respeito à retirada da autorização de certos antibióticos, a Diretiva 70/524/CEE relativa aos aditivos na alimentação para animais. Jornal Oficial das Comunidades Europeias, n. L351, p. 4-8, 1998.

[15] Brasil. Ministério da Agricultura, Pecuária e Abastecimento. Portaria no 808 de 06 de novembro de 2003. Foi instituído um grupo de trabalho (GT) pelo MAPA para analisar e reavaliar o uso das substâncias químicas: carbadox, olaquindox, bacitracina de zinco, espiramicina, viginiamicina e fosfato de tilosina como aditivos para alimentação animal. Relatório técnico final [acesso em 20 abr 2013]. Disponível em: http://www.agricultura.gov.br/animal/alimentacao.

[16] Burkin M, Galvidis I. Simultaneous separate and group determination of tylosin and tilmicosin in foodstuffs using single antibody-based immunoassay. Food Chem. 2012;132(2):1080-6.

[17] Guardabassi L, Jensen LB, Kruse H. Guia de Antimicrobianos em Veterinária. Porto Alegre: Editora Artmed; 2010.

[18] World Organization for Animal Health [homepage]. OIE List of antimicrobials of veterinary importance [acesso em 21 nov 2011]. Disponível em: http://www.oie.int/doc/en_document.php?numrec $=35337$ 03.

[19] Nisha AR. Antibiotic residues: a global health hazard. Veterinary World. 2008;1(12):375-7.

[20] Martins-Júnior HA, Kussumi TA, Wang AY, Lebre DT. A rapid method to determine antibiotic residues in milk using liquid chromatography coupled to electrospray tandem mass spectrometry. J. Braz. Chem. Soc. 2007;18(2):397-405.

[21] Martin JGP. Resíduos de antimicrobianos em leite: uma revisão. Segurança Alimentar e Nutricional. 2011;18(2):8087.

[22] Brasil. Agência Nacional de Vigilância Sanitária. Programa de Análise de Resíduos de Medicamentos
Veterinários em Alimentos de Origem Animal - PAMVet Relatório 2004/2005: Monitoramento de Resíduos em Leite Exposto ao Consumo. Brasília: ANVISA; 2006 [acesso em 20 jan 2012]. Disponível em: http://www.anvisa.gov.br/alimentos/pamvet/relat $\%$ F3rio_ leite_2004-05.pdf

[23] Silva Júnior LS. Tetraciclinas em medicamentos veterinários e produtos lácteos [tese de doutorado]. Campinas: Universidade Estadual de Campinas; 2004.

[24] Kanfer I, Skinner MF, Walker RB. Analysis of macrolide antibiotics. J Chromatogr A. 1998;812(1-2):25586.

[25] FAO. Residue Evaluation of Certain Veterinary Drugs: Joint FAO/WHO Expert Committee on Food Additives. Rome: FAO; 2009.

[26] The Merck Veterinary Manual [homepage]. Macrolides: special clinical concerns [acesso em 6 jan 2012]. Disponível em:

http://www.merckvetmanual.com/mvm/index.jsp?cfile= $\mathrm{htm} / \mathrm{bc} / 191269 . \mathrm{htm}$

[27] Compêndio de Produtos Veterinários [homepage]. Compêndio de Produtos Veterinários - Sindicato Nacional da Indústria de Produtos para Saúde Animal [acesso em 5 nov 2011]. Disponível em: http://www.cpvs.com.br/cpvs/index.html.

[28] Juan C, Moltó JC, Mañes J, Font G. Determination of macrolide and lincosamide antibiotics by pressurized liquid extraction and liquid chromatography-tamdem mass spectrometry in meat and milk. Food Control. 2010;21(12):1703-9.

[29] García-Mayor M, Gallego-Picó A, Garcinuño P, Fernández-Hernando P, Durand-Alegría J. Matrix solidphase dispersion method for the determination of macrolide antibiotics in sheep's milk. Food Chem. 2012;134(1):553-8.

[30] United States Departament of Agriculture [homepage]. Maximum Residue Limit Database [acesso em 12 out 2012]. Disponível em: http://www.mrldatabase.com

[31] MERCOSUL. GMC/RES no 54/2000. Regulamento Técnico Mercosul. Metodologias Analíticas, Ingestão Diária Admissível e Limites Máximos de Resíduos para Medicamentos Veterinários em Produtos de Origem Animal [acesso em 12 jan 2012]. Disponível em: http://www.mercosur.int/msweb/portal\%20intermediario/ Normas/normas_web/Resoluciones/PT/Res_054_000_R TM $\% 20$ Res $\%$ C3 $\%$ ADduos $\% 20$ Medic $\% 20$ Veterin $\%$ C3 $\%$ A 1rios_Ata\%203_00.pdf. 
[32] Brasil. Ministério da Saúde. Agência Nacional de Vigilância Sanitária. Diretoria Colegiada. Resolução RDC no 53, de 02 de outubro de 2012. Dispõe sobre o regulamento técnico Mercosul - Metodologias analíticas, ingestão diária admissível e limites máximos de resíduos para medicamentos veterinários em alimentos de origem animal. Diário Oficial da União, 03 out. 2012. Seção 1, p. 47.

[33] Ferreira RG, Spisso BF, Hora IMC, Monteiro MA, Pereira MU, Costa RP, Carlos, BS. Panorama da Ocorrência de Resíduos de Medicamentos Veterinários em Leite no Brasil. Segurança Alimentar e Nutricional. 2012;19(2):30-49.

[34] Brasil. Presidência da República. Casa Civil. Sub-chefia para assuntos jurídicos. Lei no 11346 de 15 set. 2006. Cria o Sistema Nacional de Segurança Alimentar e Nutricional SISAN, com vistas em assegurar o direito humano à alimentação e dá outras providências [acesso em 15 fev 2012]. Disponível em: http://www4.planalto.gov.br/consea/conferencia/docume ntos/lei-de-seguranca-alimentar-e-nutricional

[35] Brasil. Ministério da Agricultura, Pecuária e Abastecimento. Instrução Normativa no 10 de 14 de abril de 2008. Aprova os Programas de Controle de Resíduos e Contaminantes em Carnes (Bovina, Aves, Suína e Eqüina), Leite, Mel Ovos e Pescado do exercício de 2008. Diário Oficial da União, 17 abr. 2008. Seção 1, p.29-34.

[36] Brasil. Ministério da Saúde. RDC no 253 de 16 de setembro de 2003. Institui o Programa de Análise de Resíduos de Medicamentos Veterinários em Alimentos de Origem Animal - PAMVet. Diário Oficial da União, 18 set. 2003. Seção 1, p. 90-91.

[37] Brasil. Ministério da Agricultura, Pecuária e Abastecimento. Instrução Normativa no 11 de 07 de maio de 2014. Publica o Subprograma de Monitoramento em carnes (Bovina, Aves, Suína e Equina), Leite, Mel, Ovos e Pescado para o exercício de 2014, referente ao Plano Nacional de Controle de Resíduos e Contaminantes PNCRC, na forma dos Anexos I e II à presente Instrução Normativa. Diário Oficial da União, 07 mai. 2014. Seção 1, p. 5 .

[38] Freitas A, Barbosa J, Ramos, F. Development and validation of a multi-residue and multi-class ultra-highpressure liquid chromatography-tandem mass spectrometry screening of antibiotics in milk. Int Dairy J. 2013; 33(1):3843.

[39] Nagel O, Molina MP, Althaus R. Microbiological system in microtitre plates for detection and classification of antibiotics residues in milk. Int Dairy J. 2013;32(2):150-155.
[40] Nagel O, Beltránb M, Beltránb M, Althausa R. Novel microbiological system for antibiotic detection in ovine milk. Small Rumin Res. 2012;102(1):26-31.

[41] Peng D, Shengqiang Y, Wang Y, Chen D, Tao Y, Huang L, et al. Development and validation of a indirective competitive enzyme-linked immunosorbent assay for the screening of tylosin and tilmicosin in muscle, liver, milk, honey and eggs. J Agric Food Chem. 2012;60(1):44-51.

[42] Bilandizic N, Kolanovic' SB, Varenina I, Scortichini G, Annunziata L, Brstilo M, Rudan N. Veterinary drug residues determination in raw milk in Croatia. Food Control. 2011;22(12):1941-1948.

[43] Gradinaru AC, Popescu O, Solcan G. antibiotics residues in milk from Moldavia, Romania. HVM Bioflux. 2011;3(2):133-141.

[44] Karamibonari AR, Movassagh MH. Determination of tylosin residues by ELISA in pasteurized milk marketed in Tabriz. Global Veterinaria. 2011;6(6):527-9.

[45] Movassagh MH. Study of antibiotics residues in cow raw milk by copan milk test in Parsabad region, Ardabil province, Iran. Annals of Biological Research.2011;2(4):3559.

[46] Clark BS, Storey MJ. Optimization and validation of a multiclass screening and confirmation method for drug residues in milk using high-performance liquid chromatography/tandem mass spectrometry. J AOAC Int. 2011;94(2):383-93.

[47] Sanli S, Palabiyik IM, Sanli L, Guzel-Seydim ZB, Alsancak G. Optimization of the experimental conditions for macrolide antibiotics in high performance liquid chromatography by using response surface methodology and determination of tylosin in milk samples. Journal of Analytical Chemistry. 2011;66(9):838-47.

[48] Nagel O, Molina P, Althaus R. Microbial system for identification of antibiotic residues in milk. J Food Drug Anal. 2011;19(3):369-75.

[49] Su P, Liu N, Zhu M, Ning B, Liu M, Yang Z, et al. Simultaneous detection of five antibiotics in milk by highthroughput suspension array technology. Talanta. 2011;85(2):1160-5.

[50] Sokol J, Popelka P, Najy J. Determination of tylosin in food animal origin by liquid chromatography. Folia Veterinaria. 2010;54(3):167-71. 
[51] Vidal MLJ, Frenich GA, Aguilera-Luiz MM, RomeroGonzález RR. Development of fast screening methods for the analysis of veterinary drug residues in milk by liquid chromatography-triple quadrupole mass spectrometry. Anal Bioanal Chem. 2010;397(7):2777-90.

[52] Bohm D, Stachel C, Gowik P. Multi-method for the determination of antibiotics of different substance groups in milk and validation in accordance with Commission Decision 2002/657/EC. J Chromatogr. A. 2009;1216(46):8217-23.

[53] Althausa R, Berrugab IM, Monteroc A, Rocac M, Molinac PM. Evaluation of a microbiological multi-residue system on the detection of antibacterial substances in ewe milk. Anal Chim Acta. 2009;632(1):156-62.

[54] Sierra D, Contreras A, Sanchez A, Luengo C, Corrales JC, Morales CT, et al. Short communication: detection limits of non- $\beta$-lactam antibiotics in goat's milk by microbiological residues screening tests. J Dairy Sci. 2009;92(9):4200-6.

[55] Stolker A, Rutgers P, Oosterink E, Rutgers J, Peters R, Rhijn J, Nielen M. Comprehensive screening and quantification of veterinary drugs in milk using UPLC-ToFMS. Anal Bioanal Chem. 2008;391(6):2309-22.

[56] Turnipseed BS, Andersen CW, Karbiwnyk MC, Madson RM, Miller EK. Multi-class, multi-residue liquid chromatography/tandem mass spectrometry screening and confirmation methods for drug residues in milk. Rapid Commun Mass Spectrom. 2008;22(10):1467-80.

[57] Aguilera-Luiz M, Vidal J, Romero-González R, Frenich A. Multi-residue determination of veterinary drugs in milk by ultra-high-pressure liquid chromatography-tandem masss pectrometry. J Chromatogr. A. 2008;1205(1-2):10-6.
[58] Mohsenzadeh M, Bahrainipour A. The detection limits of antimicrobial agents in cow`s millk by a simple yoghurt culture test. Pak J Biol Sci. 2008;11(18):2282-85.

[59] Bang-Ce Y, Songyang L, Peng Z, Xiao-Hong L. Simultaneous detection of sulfamethazine, streptomycin, and tylosin in milk by microplate-array based SMM-FIA. Food Chem. 2008;106(2):797-803.

[60] Wang J, Leung D. Analyses of macrolide antibiotic residues in eggs, raw milk and honey using both ultraperformance liquid chromatography/quadrupole time-offlight mass spectrometry and high-performance liquid chromatography/tandem mass spectrometry. Rapid Commun Mass Spectrom. 2007;21(19):3213-22.

[61] Linage B, Gonzalo C, Carriedo JA, Asensio JA, Blanco MA, De La Fuente MF, et al. Performance of blue-yellow screening test for antimicrobial detection in ovine milk. J Dairy Sci. 2007;90(12):5374-9.

[62] Litterio N, Calvinho L, Flores M, Tarabla H, Boggio J. Microbiological screening test validation for detection of tylosin excretion in milk of cows with low and high somatic cell counts. J Vet Med A. 2007;54(1):30-5.

[63] Mamani MCV. Desenvolvimento e validação de métodos para a determinação de antimicrobianos em leite e fármacos usando a cromatografia líquida de alta eficiência e eletroforese capilar [tese de doutorado]. Campinas: Universidade Estadual de Campinas; 2007. 